18

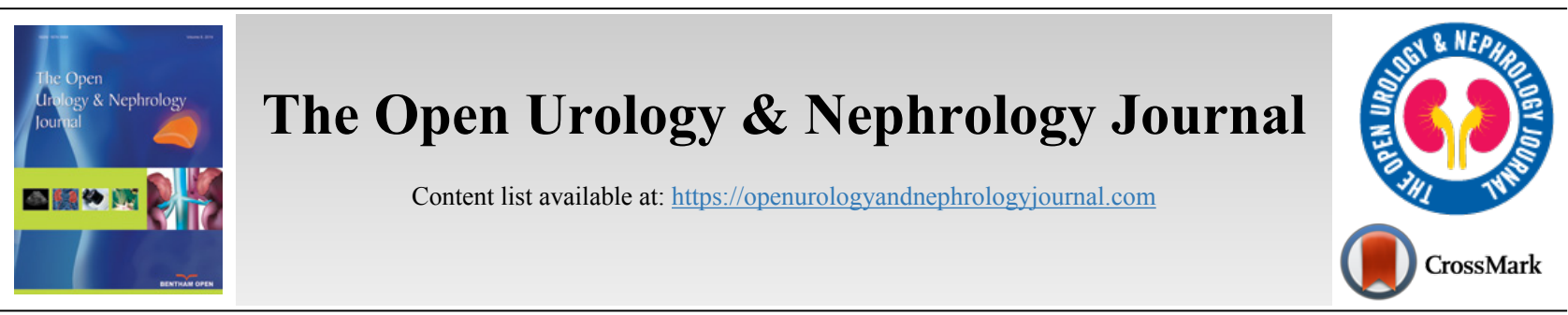

CASE REPORT

\title{
A Successful Management of Supra-Renal Inferior Vena Cava Injury Following Penetrating Trauma: A Case Report
}

\author{
Abdikarim Hussein Mohamed ${ }^{1, *(D)}$ and Aşır Eraslan ${ }^{2}$

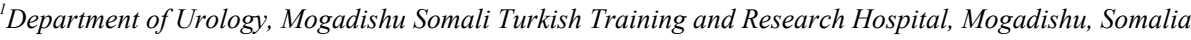 \\ 2Department of Urology, Dıșkapı Yildirim Beyazit Training and Research Hospital, Ankara, Turkey
}

\begin{abstract}
Penetrating trauma of the abdominal Inferior Vena Cava remains a life-threatening injury. Nearly half of patients with an injury of abdominal Inferior Vena Cava die before reaching the hospital. This makes injuries of IVC often fetal and the management of these injuries is usually challenging. Early hospital transfer, prompt diagnosis, rapid bleeding control and diminishing shock period remain significantly important factors that improve the survival rate. We report a successful surgical management of suprarenal inferior vena cava injury case and associated organ injuries following a stab knife wound.
\end{abstract}

\begin{tabular}{|l|c|c|c}
\hline Article History & Received: January 15, 2020 & Revised: May 13, 2020 & Accepted: May 14, 2020
\end{tabular}

\section{INTRODUCTION}

Inferior Vena Cava (IVC) injuries are highly fatal with mortality rates between 70 and 90\% [1]. Most abdominal vascular injuries result from penetrating trauma. Intraoperative bleeding and concomitant injuries are recognized as responsible for the majority of deaths. The surgical management of these concurrent injuries is usually challenging. Most of these patients are hemodynamically unstable [2]. We present a case of a stabbing knife wound injury of supra-renal IVC managed primary repair with good outcome results.

\section{CASE REPORT}

A 24-year old man was the victim of a large knife stab wound sustained five hours before the arrival of the hospital. On admission, the patient was in hypovolemic shock. Physical examination was carried out in which blood pressure of $85 \backslash 40$ $\mathrm{mmHg}$ despite intravenous (IV) resuscitation, and distended abdomen with guarding and tenderness were noted. There was a right side wound of entry in the posterior ninth intercostal space lateral to the mid-axillary line. Upon arrival, a urethral catheter was inserted and gross hematuria was detected. Laboratory results reveal hemoglobin of $9.9 \mathrm{mg} / \mathrm{dl}$ and hematocrit of $27 \%$. Abdominal Computed Tomography (CT) with contrast revealed Grade IV renal injury with perirenal hematoma Figs. (1 and 2). Urgent laparotomy was performed.

\footnotetext{
* Address correspondence to this author at the Department of Urology, Mogadishu Somali Turkish Training and Research Hospital, Mogadishu; Somalia; Tel: 615167182; E-mail address: abdikarimgabeyre@gmail.com
}

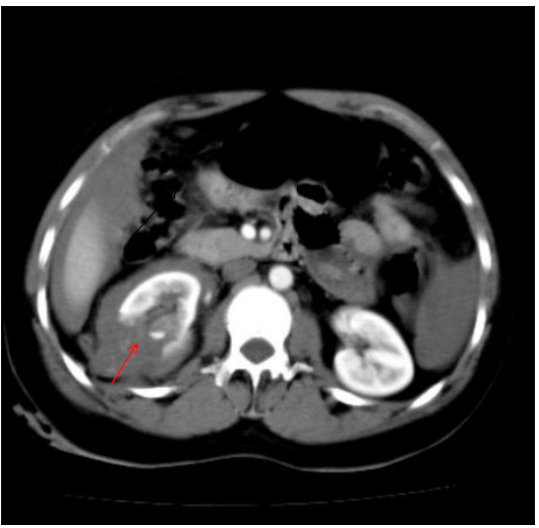

Fig. (1). Contrast enhanced $\mathrm{Ct}$ of the abdomen reveals grade 4 renal injury with perirenal hematoma (arrows).

The intra-abdominal findings were: 2 litters of blood at exploration with active bleeding from the upper retroperitoneum, a large retroperitoneal hematoma and active bleeding around the right kidney arising from renal vascular injuries, liver injury around the lower lobe. Prompt right nephrectomy was performed with the continuation of exploration to verify the cause of the active bleeding. Upon exploration, $5 \mathrm{~cm}$ anterior vertical cut was identified on the supra-renal inferior vena cava without evidence of injury to the posterior wall of vena cava (Fig. 3). The bleeding was controlled with the use of vascular clamps and the vena cava cut was repaired with the use of 6-0 polypropylene suture. The liver injury was repaired and the bowel was inspected. Intraoperatively, the patient was transfused with resuscitation 
fluids, erythrocyte products, fresh frozen plasma and platelets due to the massive bleeding encountered perioperatively. Postoperatively the patient was taken to the surgical intensive care unit for four days and afterward to the urology department. The postoperative period was uneventful; the drain was removed on the fifth day and discharged on the 11th day $[1,2]$.

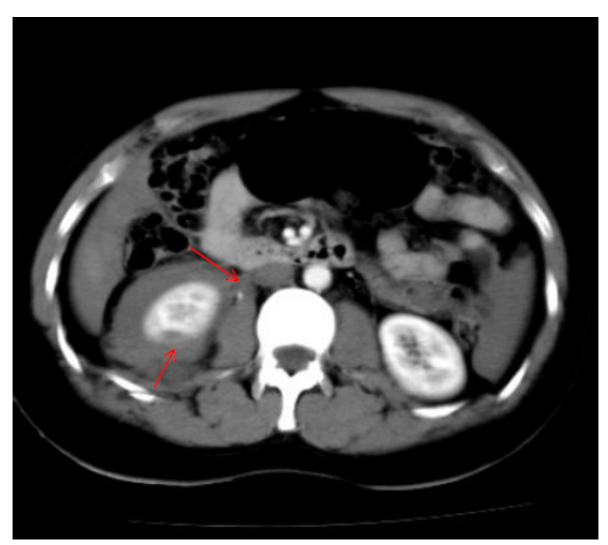

Fig. (2). Contrast enhanced $\mathrm{Ct}$ of the abdomen also reveals laceration of renal vein to the inferior vena cava (arrows).

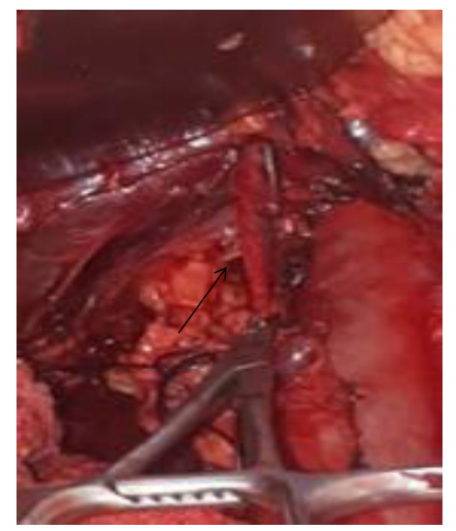

Fig. (3). Inferior vena cava injury site (arrows).

\section{DISCUSSION}

Injuries of the inferior vena cava are often fatal, and resulting in death most commonly caused by intraoperative exsanguination. This case report illustrates a rare stab knife wound injury to the suprarenal inferior vena cava with excellent results. More than one-third of patients with an abdominal vena cava injury will not survive to reach the hospital alive; another third will die within $24 \mathrm{~h}$ of treatment from complications of massive hemorrhage and/or associated multiple intra-abdominal injuries [3]. The current case presents a penetrating injury of the upper retroperitoneum caused a high grade right kidney and supra-renal vena cava injury leading to massive intra-abdominal bleeding. The bleeding was controlled with the performance of right nephrectomy, repair of vena cava and liver injuries.

There are fewer other similar cases to this one in the literature. In one particular case report, Prafull Shah et al. reported a case of isolated IVC injury due to deceleration injury treated by right nephrectomy [4]. Primary repair of suprarenal IVC is the preferred surgical method, the option of IVC ligation can be used at life-saving situations. Ligation is associated with similar mortality rate according to propensity score matching with significant complication rates [5]. Location of the vena cava injury is an important predictor for survival. Infrarenal location is associated with the lowest mortality rate $(23 \%)$, whereas both suprarenal and retrohepatic locations are associated with a higher mortality rate reaching $70 \%$. Thomaz et al. presented 12 cases of inferior vena cava injuries with one mortality which was the only supra-renal IVC site injury in that cohort [6]. Additional prognostic factors are the hemodynamic status at admission and the presence of active bleeding at laparotomy. A recent comparison of survivors vs. non-survivors confirmed that patients who arrive in shock and those who are still actively bleeding at the time of laparotomy have the worst outcomes [7]. It is very imperative to aware that the reporting case had hypotension and active bleeding due to supra-renal vena cava penetrating injury. Prompt surgical intervention and bleeding control is the most significant factor for patient survival.

\section{CONCLUSION}

Due to the severity of these injuries, management of these injuries is usually challenging especially in developing countries where there are scarcities of high trauma centers. Early hospital transfer, prompt diagnosis, rapid bleeding control and diminishing shock period remains significantly important factors that improve the survival rate.

\section{ETHICS APPROVAL AND CONSENT TO PARTI- CIPATE}

Not applicable.

\section{STANDERED OF REPORTING}

CARE guidelines and methodology has been followed.

\section{CONSENT FOR PUBLICATION}

Written informed consent was obtained from all the participant.

\section{FUNDING}

None.

\section{CONFLICT OF INTEREST}

The authors declare no conflict of interest, financial or otherwise.

\section{ACKNOWLEDGEMENTS}

Declared none.

\section{REFERENCES}

[1] Cheaito A, Tillou A, Lewis C, Cryer H. Management of traumatic blunt IVC injury. Int J Surg Case Rep 2016; 28: 26-30. [http://dx.doi.org/10.1016/j.ijscr.2016.09.003] [PMID: 27668552]

[2] Hashempour MR, Motalebi R, Mosallami SM, Mortazavi N. A successful management of juxta-renal inferior vena cava injury after penetrating trauma: A case report. J Trauma Treat 2016; 5: 334. [http://dx.doi.org/10.4172/2167-1222.1000334] 
[3] Navsaria PH, de Bruyn P, Nicol AJ. Penetrating abdominal vena cava injuries. Eur J Vasc Endovasc Surg 2005; 30(5): 499-503. [http://dx.doi.org/10.1016/j.ejvs.2005.08.004] [PMID: 16168684]

[4] Prafull S, Namrata S. Penetrating abdominal trauma - A case of isolated inferior vena cava injury. Bombay Hosp J 2008; 50(2)

[5] Matsumoto S, Jung K, Smith A, Coimbra R. Management of IVC Injury: Repair or Ligation? A Propensity Score Matching Analysis Using the National Trauma Data Bank. J Am Coll Surg 2018; 226(5): 752-759.e2.

[http://dx.doi.org/10.1016/j.jamcollsurg.2018.01.043]

[PMID: 29408285

[6] Starzl TE, Kaupp HA, Beheler EM, Freeark RJ. The treatment of penetrating wounds of the inferior vena cava. Surgery 1962; 51(2): 195-204.

[7] Kuehne J. Determinants of survival after inferior vena cava trauma. The American Surgeon; Atlanta 1999; 65(10): 976-81.

(C) 2020 Mohamed and Eraslan.

This is an open access article distributed under the terms of the Creative Commons Attribution 4.0 International Public License (CC-BY 4.0), a copy of which is available at: https://creativecommons.org/licenses/by/4.0/legalcode. This license permits unrestricted use, distribution, and reproduction in any medium, provided the original author and source are credited. 